\title{
NOÇÃO DE PESSOA: apontamentos sobre um alargamento teórico possível
}

\author{
Flora Rodrigues Gonçalves ${ }^{1}$
}

\begin{abstract}
"Colocar-se na posição de autor é testemunhar o mundo através de olhos diferentes; mas o que é visto tem de ser provisório devido ao próprio ato de conscientização que ocorre ao assumir o ponto de vista de outra pessoa."
\end{abstract}

Marilyn Strathern

\begin{abstract}
Resumo
O objetivo deste artigo é contribuir para suscitar reflexões sobre autoria e seus demais agenciamentos a partir da compreensão de que a autoria, tal como a concebemos e vivenciamos, é uma forma de experimentar o mundo. Uma abordagem antropológica da noção de autoria ou do autor parte, necessariamente, do entendimento de que a noção de autoria foi etnograficamente e historicamente circunscrita no conceito de pessoa. Porém, é preciso por em evidência a noção de pessoa nas sociedades ocidentais. As noções de pessoa que fogem da construção "ocidental" são extremamente significativas e podem auxiliar na própria compreensão de propriedade(s) intelectual(ais) realizada(s) e representada(s) além e aquém do nosso arcabouço legal e moral sobre autoria e indivíduo.
\end{abstract}

Palavras-chave: Noção de pessoa, direito autoral, propriedade intelectual, autoria

\begin{abstract}
The aim of this article is to contribute to the reflections about authorship and its remaining agencies, assuming that authorship, as we conceive and live it, is a way of experimenting the world. An anthropological appproach of the notion of authorship or that of the author assumes, necessarily, that the notion of authorship has been ethnographically and historically circunscribed in the concept of person. However, it is necessary to put in evidence the notion of person in Western societies. The notions of person that escape the "Western" construction are extremely meaningful and may help in the in the understanding of intelectual property(ies) itself, carried out and represented beyond and below our legal and moral framework about authorship and individual.
\end{abstract}

Keywords: Notion of person, copyright, intelectual property, authorship

\footnotetext{
${ }^{1}$ Possui graduação em Ciências Sociais pela Universidade Federal de Minas Gerais (2007) e Mestrado em Antropologia Social pela Universidade Federal de Minas Gerais (2010). Atualmente, é aluna de doutoramento no Programa de Pós-Graduação em Antropologia da UFMG. Tem experiência na área de Antropologia, com ênfase em Antropologia e Propriedade Intelectual, atuando principalmente nos seguintes temas: antropologia simétrica, cultura popular, ciência e tecnologia estudo de controvérsias. E-mail: florazappa@gmail.com
} 


\section{Algumas Considerações sobre a noção de pessoa}

A noção de pessoa tal como compreendemos hoje é uma construção histórica que permitiu, ao longo de um certo período de tempo, um sistema de ordenamento sobre a própria noção do eu e sua forma de compor o mundo. O primeiro ponto que apreendemos é que a noção de pessoa é contextual. Marcel Mauss (2003) foi quem nos mostrou como a noção de pessoa, do indivíduo e do "Eu", como ele mesmo chamou, adquiriu sentidos diferentes em sociedades variadas. O ponto importante assinalado por Mauss (2003) era que, em todas as sociedades por ele pesquisadas, a noção de pessoa estava presente e representada em alguma medida. Sendo assim, desde os pueblos e sua noção de individualidade confundida com a figura do clã, passando pelo início da civilização latina que incorporou uma certa imagem de persona dentro da fabricação de sua individualidade, a noção de pessoa é uma categoria que nos acompanha e estabelece todo o universo de compreensão da nossa própria noção de indivíduo.

Mauss (2003) oferece um "catálogo das formas" que a noção de pessoa abarcou ao longo das "civilizações". Sua pesquisa parte da compreensão do lugar da pessoa entre os índios Pueblos e da importância do clã na configuração desta noção, que é baseada no papel exercido por cada indivíduo na totalidade prefigurada do grupo. O personagem que é construído nessa relação é, portanto, o ponto de partida de Mauss. A partir do personagem é que se pode pensar uma noção de pessoa além da máscara, como uma forma elementar de ordenamento no mundo. Mais do que tudo isso, a pessoa é um fato fundamental de direito, parte de uma construção Latina e "resultado de uma evolução particular do direito romano" (MAUSS, 2003, p. 383). Conseguinte, ao direito moral adiciona-se o sentido jurídico e cristão, mas a noção de pessoa ainda haveria de sofrer "uma outra transformação para tornarse o que ela se tornou há menos de um século" (MAUSS, 2003, p. 392), e é aqui que o autor acrescenta, apoiado no cristianismo e na herança kantiana, a categoria do Eu e toda a cartografia de uma existência da consciência individual:

\footnotetext{
"De uma simples mascarada à mascara; de um personagem a uma pessoa, a um nome, a um indivíduo, deste a um ser com valor metafísico e moral; de uma consciência moral a um ser sagrado, deste a uma forma fundamental do pensamento e da ação; foi assim que o percurso se realizou." (MAUSS, 2003, p. 395)
}

Porém, como assinala Márcio Goldman (1999), se para nós parece ser evidente que a noção de pessoa varia para cada sociedade estudada, "a noção desta noção não parece variar 
menos de antropólogo para antropólogo" (GOLDMAN, 1999, p. 12). A perspectiva evolutiva da noção de pessoa no trabalho de Mauss (2003), aliada ao fato de que, ao mesmo tempo, a construção dessa noção também deve ser relativizada segundo as sociedades estudadas, diverge de muitos outros antropólogos que se dedicaram aos estudos sobre a pessoa. Segundo Goldman (1999), Levy-Bruhl, por exemplo, não traça uma evolução ao estilo de Mauss, se dedicando a compreender como chegamos a tal conceito sem tornar presente a progressão proposta por Mauss.

“(...) Para compreender como chegamos a uma noção de pessoa em si, seria preciso abandonar o postulado de uma lenta evolução ascendente, substituindo-o pela hipótese de uma mutação de ordem mental que teria feito com que passássemos a ver seres individuais lá onde os primitivos enxergavam apenas relações e participações totais" (GOLDMAN, 1999, p.13).

Para Levy-Bruhl (1947), a noção de pessoa não foi construída evolutivamente, com pequenos ou pontuais acréscimos de uma dada "civilização". Para esse autor, a noção de pessoa na mentalidade "primitiva" e sua noção pré-lógica operava em uma perspectiva radicalmente diferente daquela operada em nossa sociedade. Segundo ele, as sociedades "primitivas" compreendiam a noção de pessoa como um lugar das relações e participações totais, diferente da sociedade ocidental que a compreende como indivíduo. A passagem de uma noção de pessoa para a outra se daria por uma mutação de ordem mental a qual deveria (ainda) ser devidamente etnografada.

A partir de Levy-Bruhl (1947), e em alguma medida do próprio Marcel Mauss (2003), compreendemos que a noção de pessoa é, nas sociedades ocidentais ${ }^{2}$, correlata da noção de indivíduo. Convém lembrar que essa discussão já estava presente, alguns anos antes, na sociologia durkheimiana acerca das representações. Para Émile Durkheim (1970) - assim como para Mauss, a noção do indivíduo emerge na medida em que a sociedade vai se complexificando: nas pequenas sociedades, onde o clã é a unidade sociológica, o indivíduo ainda se confunde com o grupo ${ }^{3}$. Segundo Durkheim (1970), a partir de um dado momento,

\footnotetext{
2 A escolha de "ocidental" parte da compreensão já desenvolvida por Marilyn Strathern (2006), que entende por ocidental "o conjunto de ideias que deriva de uma fonte social com sua natureza própria, específica e singular, por contraste com a derivação das ideias melanésias" (38:2006). Para saber mais, ver Strathern, Marylin (2006) "Estratégias antropológicas". In. O gênero da Dádiva: Problemas com as mulheres e problemas com a sociedade Melanésia.

${ }^{3}$ Como vimos, esse não é um argumento novo. Mauss e grande parte da antropologia francesa parte do sistema de representações de Durkheim para formular seus estudos sobre pessoa, na tentativa de compreender a história
} 
quando a sociedade já não repousa sobre a solidariedade mecânica e transforma o grupo em estruturas complexas, a nossa noção de indivíduo, tal como a concebemos hoje, surge.

Em uma análise mais específica, Louis Dumont (1997) faz, a partir de suas pesquisas sobre as sociedades indianas, um vasto trabalho sobre a constituição do "indivíduo" na sociedade ocidental. Dumont (1997) acredita na construção histórica da noção de pessoa, a qual ele chama de "indivíduo", e faz um trabalho importante ao problematizar a relação indivíduo e sociedade a partir dos seus estudos sobre o sistema de castas indiano e as sociedades ocidentais. É o antropólogo que define, de maneira cabível, a concepção ocidental moderna de pessoa que atualmente compartilhamos, do homem como "indivíduo-no-mundo", um “indivíduo valor” que é a essência da humanidade. Desse modo,

"O ser humano é o homem "elementar", indivisível, sob sua forma de ser biológico e ao mesmo tempo de sujeito pensante. Cada homem particular encarna, num certo sentido, a humanidade inteira." (DUMONT, 1997, p. 57)

Para Dumont (1997), a sociedade moderna é uma sociedade individualista. Isso significa que a raiz do pensamento ocidental é a noção de indivíduo como ser moral, autônomo, estabelecido como uma entidade singular (em comparação) possível. Em um artigo de 1977, Eduardo Viveiros de Castro e Ricardo Benzaquen de Araújo sugerem, em contrapartida a Dumont e a Shakespeare, uma abordagem antropológica da noção de amor, que só é possível a partir da moderna concepção de mundo onde o indivíduo é a categoria central. Afirmam os autores que

"A noção de amor elaborada no texto em questão define uma concepção particular das relações entre indivíduo e sociedade, estando subordinada a uma imagem básica da cultura ocidental - a do indivíduo liberto dos laços sociais, não mais derivando sua realidade dos grupos a que pertença, [grifo meu] mas em relação direta com um cosmos composto de indivíduos, onde as relações sociais valorizadas são relações interindividuais". (VIVEIROS DE CASTRO; BENZAKEN DE ARAÚJO, 1977, p. 131)

Qual o espaço cedido ao indivíduo dentro dos modelos analíticos da antropologia? Clifford Geertz (2012) parece apontar para um entendimento sobre a questão. Ao estudar a noção de pessoa em três sociedades distintas, Geertz (2012) compreende que a pessoa é uma noção contextual, e cumpre conceber sua experiência em determinada sociedade. Segundo Geertz (2012, p. 63), 
"Em todas as três sociedades que estudei intensivamente, a javanesa, a balinesa e a marroquina, tive como um dos meus objetivos principais tentar identificar como as pessoas que vivem nessas sociedades se definem como pessoas, ou seja, de que se compõe a ideia que elas têm do que é um "eu" no estilo javanês, balinês ou marroquino. (...) $\mathrm{O}$ conceito de pessoa é uma constante universal em qualquer sociedade, que variam de um grupo para outro, com diferentes profundidades entre elas. (...) É minha experiência que a concepção do que é indivíduo humano, em contraste com o que é uma pedra, um animal, uma floresta tropical, ou um deus, é um fenômeno universal".

Se em toda e qualquer sociedade existe uma certa noção de pessoa, como compreender a nossa concepção de indivíduo e apreender as complexas relações que surgem ao acionarmos tal conceito? Como nos lembra Goldman (1999), é preciso um alargamento das noções de indivíduo e de pessoa. É preciso ir além.

Mauss (2003), Levy-Bruhl (1947), Dumont (1997), Geertz (2012), entre outros, foram antropólogos que contribuíram para a constituição dos estudos sobre pessoa dentro da disciplina. Porém, percebemos que a história de um conceito, em alguma medida, traz à tona as diferenças e assimetrias que o acompanham. Certamente, a noção de pessoa nas sociedades ocidentais, convencionada legalmente em um emaranhado de conceitos que definem o indivíduo em certa medida como autor, detentor, ou, ainda, como portador de certo tipo de propriedade, é também problemática e suscita uma série de questões que tratam, fundamentalmente, da compreensão da pessoa moderna enquanto indivíduo - e toda a discussão que essa unicidade nos traz. Assim como Michel Foucault (1969), permitimos interrogar o que certas noções dizem ou o que querem dizer. E principalmente, o que dizem sobre elas. Tal é a complexidade da questão.

É preciso por em evidência a noção de pessoa nas sociedades ocidentais. A noção legal de pessoa "moderna" é parte construtiva do nosso direito autoral. Porém, a construção da figura do autor, tal como a noção de pessoa, está intrinsecamente amalgamada ao nosso direto de propriedade - e aspirar uma noção de autor diferente disso leva tempo e implica diversos agenciamentos.

Percebemos por meio da antropóloga Marylin Strathern (2014) que a autoria é compreendida através da propriedade, em termos de produção e controle. Marylin Strathern (2014), em paralelo com a cultura Hagen, observa que a cultura "burguesa ocidental" envolve um modelo de partilha e de troca que está calcada na noção de que produção é controle, inclusive o controle atribuído a coisas - como vemos na propriedade intelectual e na 
compreensão legal de autoria e de autor contemporâneos. A autora considera que o desenvolvimento das leis que envolvem a propriedade intelectual fundou-se na "afirmação da paternidade dos autores em relação aos produtos" (2014, p. 297), preservando a separação entre as pessoas e o que pode ser possuído.

O que compreendemos - e compreendemos bem - é que, em algum momento da história, nossa noção de pessoa se alicerçou no direito jurídico e moral do autor. Segundo Mauss (2003, p. 388-389).

“(...) Acrescenta-se cada vez mais um sentido moral ao sentido jurídico, um sentido de ser consciente, independente, autônomo, livre e responsável. A consciência moral introduz a consciência na concepção jurídica do termo".

O indivíduo moral, em sua autoridade, converge para a convenção jurídica que aqui nos interessa tanto: o direito autoral.

O direito autoral é um instrumento jurídico criado para resguardar o direito do autor, do criador, à reprodução e forma de distribuição de suas criações. Nesse sentido, enquanto instituição jurídica, o direito de autor é um direito à propriedade, em sua acepção mais comum do termo: direito fundamental a ter a coisa própria.

Porém, diferentes noções de autoria aparecem para compor as mais plurais formas de experimentação autorais. Se até aqui compreendemos como a noção de pessoa e seu correlato - o indivíduo -, vêm sendo fabricados ao longo do tempo e trabalhados na matriz antropológica, noções outras sobre a própria construção da autoria aparecem como condição (política) de existência de coletivos que não participam da atribuição classificatória que tal conceito exerce em nossa sociedade.

Supomos, tal como Michel Foucault (1969), que o autor - ou o seu nome - não é apenas um elemento do enunciado; ele caracteriza um modo de existência, de circulação e funcionamento de alguns discursos no interior da sociedade. O "nome do autor", ou seja, a atribuição de autoria exerce uma função classificatória, que delimita ou nomeia quem é o autor e, consequentemente, quem não o é. Porém, outras noções de autoria são possíveis e sua prática deve ser compreendida como uma elaboração crítica de experiências que propõem uma forma nova de entendimento não só da autoria, mas da própria posse (e propriedade) que circunscreve seu significado.

\section{Autoria, propriedade intelectual e direito autoral: breves considerações}


A lei 9.610 de 19 de fevereiro de 1998, que regulamenta os direitos autorais, entende, em seu artigo 11, que o autor é a pessoa física criadora de obra literária, artística ou científica. Essa mesma lei é acionada frequentemente em casos muito complexos de plágio, fabricação de dados de pesquisas acadêmicas, falsificação de obras de arte e editoração ou publicação de obras intelectuais das mais diversas, mas nem sempre foi assim.

A construção da figura do autor aparece na história ocidental de forma mais consolidada no final do século XVII, impulsionada pelo projeto cartesiano do indivíduo e, em certa medida, pelas discussões acerca dos direitos de autor entre livreiros e a Igreja Católica. Segundo Antônio (1998, p. 189),

"A construção desse autor está ligada ao interesse principalmente religioso (da igreja cristã) de conferir um determinado valor e uma ordem particular a um discurso, com o propósito de institucionalizá-lo, transformando-o em um discurso competente (...)"

A partir das bases racionalistas de René Descartes (2001), o iluminismo também contribuiu para alicerçar a noção de autor que hoje é amplamente conhecida. Porém, é importante evidenciar que a figura do autor tal como conhecemos vem sendo fabricada desde muito antes, com os copistas medievais e até mesmo com a própria consolidação da escrita. Certamente, é eloquente afirmar que a noção de autoria que compartilhamos parte do fortalecimento da (noção de) propriedade privada, que, segundo John Locke, fundamenta a ideia que temos de "homem" ou de indivíduo moral, tal como Mauss (2003) descreve.

Como explorado pelo antropólogo Guilherme Radomsky (2012), a sistematização da noção de propriedade privada, segundo uma lógica de pertencimento, surgiu com Locke. Ao postular que o ser humano só teria propriedade sobre o seu corpo, Locke justifica o entendimento da conexão entre o trabalho que pertence a alguém, a criatividade como trabalho e sua constituição como direito de posse. Segundo o autor,

\footnotetext{
"Locke, Diderot e outros filósofos foram responsáveis por secularizar a teoria do conhecimento, mostrando que ele deveria ser interpretado como resultado do trabalho do pensamento. Como era na mente individual que se localizavam as criações, seria justo que o ser humano tivesse propriedade sobre ideias" (RADOMSKY, 2012, p. 157).
}

Podemos ir além. Desde o primeiro cercamento, quando se abandonam os commons e os pequenos pedaços de terras são arrendados em um sistema feudal ainda nascente, a propriedade privada nasce como uma potência difícil de ser ignorada. Friedrich Engels, baseado na antropologia evolucionista de Lewis Morgan em Ancient Law, considera que o 
início da propriedade privada é o início do Estado. Isso porque, segundo Morgan (2005), apesar da humanidade percorrer um só caminho desde sua origem, ela apresenta uma certa evolução gradual de seus poderes morais - e mentais - que seguem níveis de complexidade visíveis desde os tempos da selvageria. A ideia de propriedade é, então, formada lentamente desde os tempos das instituições domésticas arcaicas, se desenvolvendo melhor nos períodos subsequentes da barbárie até chegar ao começo da civilização, com a adoção de um conceito mais pragmático e legal de propriedade privada. Se a propriedade coletiva era um sinal de "involução", segundo Morgan (2005) a chamaria, o status social e estrutural que o conceito de propriedade privada hoje carrega é herança de uma série de construções legitimadas durante uma long duree ocidental que carregamos e replicamos todas as vezes em que agenciamos o conceito ${ }^{4}$.

Assim como o indivíduo, a propriedade privada também tem seu caminho - não pouco controverso. Porém, o caminho traçado por ambos se cruza e traduz, em sintonia, o indivíduo compreendido através da propriedade - não só a propriedade privada, mas a propriedade intelectual, além de uma autoria pensada, no ocidente, em termos de produção e controle. Para Marylin Strathern (2014, p. 363):

“(...) Estabelecer propriedade é uma questão de criar reinvindicações pessoais sobre elas. (...) Os direitos de propriedade aparecem como posse de pessoas e ao mesmo tempo separando, nesse ato, as pessoas umas das outras."

Mas, assim como a noção de pessoa, de indivíduo e de propriedade passaram por operações diversas de agenciamentos e compreensões ao longo do tempo, a noção de autor e autoria também sofreram um processo parecido de transformação a partir do Renascimento.

Nas artes plásticas, por exemplo, até o Modernismo, era comum que as obras de arte seguissem um padrão de imitação sem registrar o autor original. Mas antes disso, nas escolas renascentistas, o autor não era necessariamente aquele quem assinava a obra, mas aquele que participava da escola. O fato é que a autoria como nos é colocada não era problematizada. Se os conceitos como indivíduo ou individualismo se consolidaram no Renascimento, certamente a criação da imprensa foi um ponto fundamental para o estabelecimento de tais conceitos e da

\footnotetext{
${ }^{4}$ A ideia de que um acúmulo das economias de subsistência pelo "homem primitivo" foi o cerne da propriedade privada nos soa desconfortável. Semelhante desconforto é encontrado na obra de Pierre Clastres e em seu debate sobre a existência (ou não) de uma economia de subsistência pautada nas necessidades básicas em um cenário de escassez.
}

INTRATEXTOS, Rio de Janeiro, vol. 10, n.1, 2019, p. 1-17. ISSN 2176-6789. DOI: 
noção de autoria como conhecemos hoje.

O desenvolvimento das técnicas de impressão também foi imprescindível para a invenção de uma noção de autor ou de uma autoria mais consistente. A imprensa tipográfica de Guttemberg, "inventada” em 1430, além de popularizar o acesso aos livros através de sua reprodutibilidade, auxiliou na consolidação de um mercado editorial que foi fundamental para se pensar não apenas a noção de autor, mas seus direitos e suas formas legais de submissão.

A convenção jurídica que circunscreve o direito autoral nasce inicialmente como um direito concedido a livreiros, com o objetivo de centralizar as obras de literatura e controlar a circulação de escritos críticos à monarquia. Atualmente, o direito autoral no Brasil é respaldado por uma série de convenções legais, sendo a principal a Lei de Direitos Autorais (9.610/1998), além de diversos acordos e tratados internacionais que estabelecem o reconhecimento dos direitos autorais em esfera global, como a Convenção de Berna (1886) e os TRIPS (Trade-Related Aspects off Intellectual Property), aprovado em 1994.

Porém, muitas formas de autoria - e de direitos - não cabem nessas convenções legais e transcendem o debate jurídico sobre propriedade intelectual. Discussões recentes sobre uma "certa" propriedade intelectual no contexto ameríndio podem nos ajudar a compreender uma autoria que é incapaz de ser pensada em termos de unidade, contraditoriamente ao direito autoral, que pensa na exclusividade do indivíduo enquanto autor ou criador de uma obra original.

\section{Outras noções de autoria além da propriedade: um alargamento (de fato) da noção de pessoa}

Anthony Seeger, Roberto da Mata e Eduardo Viveiros de Castro já assinalavam, em 1979, que a originalidade das sociedades indígenas estava na elaboração diferencial - e relacional - da noção de pessoa em suas experiências sociais. Os autores insistiam que a realidade indígena resiste à aplicação de conceitos e modelos analíticos que consideram como base as premissas "ocidentais" de pensamento, modelos esses que foram aplicados à sua realidade ao longo dos anos por inúmeros antropólogos e pesquisadores.

A noção de pessoa ameríndia passa por uma constituição relacional que leva em consideração não apenas a fabricação de uma noção corporal de pessoa, mas também a extensão dessa fabricação aos objetos, "aparecendo, pois, como extensões de sua própria identidade" (COELHO DE SOUZA, 2012). De fato, a nossa noção proprietária de pessoa 
moderna - o indivíduo - não abarca uma relação onde os objetos possam ser compreendidos além de coisas. Aqui, o que vemos é um marco fundamental onde os objetos podem ter um princípio que lhe é próprio, e não se apresentem enquanto coisas apenas, mas como pessoas. Segundo Marcela Coelho de Souza (2012, p. 248), as sociedades ameríndias funcionam onde

"Pessoas" e "coisas" sendo sempre feitas da vontade de outras pessoas, umas e outras aparecem portanto como índices de capacidades e poderes, de agências para cuja apreensão se volta a prática explícita dos sujeitos."

Considerar a agência não-humana ${ }^{5}$ nos termos ameríndios, como um deslocamento, um movimento simétrico de composição do mundo, é parte fundamental da compreensão da noção de pessoa indígena. Em consequência, a autoria desses povos participa do mesmo registro, sendo um locus plural e relacional. Isso significa contrastar o indivíduo autoral ocidental enquanto entidade singular e as pluralidades autorais do universo ameríndio. Alguns contextos de fabricação da pessoa como a dos araweté, a partir da morte dos ta'äwé terrestre e celeste e dos deuses canibais (VIVEIROS DE CASTRO, 1986), e dos krahó, que também traçam uma lógica complexa entre a morte/lugar de origem/fabricação da pessoa (CARNEIRO DA CUNHA, 1978), são exemplos de noções outras de pessoa que seriam inconcebíveis na sociedade ocidental.

Em outro registro, para os Hagen das Terras Altas Ocidentais de Papua-Nova Guiné, a noção de pessoa participa de uma formulação bastante oposta ao indivíduo "moderno"6. Marilyn Strathern (2006) argumenta que, de maneira geral e hegemônica, o indivíduo é visto como conceitualmente distinto da sociedade, ou seja, a sociedade é vista como a parte coletiva e socializadora que relaciona os indivíduos entre si, de forma ordenada e classificatória. Assim, a "sociedade é vista como aquilo que conecta os indivíduos entre si, as relações entre eles. (...) As pessoas recebem a marca da sociedade (...) Mas, como indivíduos, são

\footnotetext{
${ }^{5}$ Como nos adverte Bruno Latour (2012), o uso da expressão "não-humano" não tem um significado em si mesma - sendo, também, fabricada e contextualizada. Segundo o autor, "(o não-humano) não designa um domínio da realidade. Não se refere a duendes de gorro vermelho agindo nos níveis atômicos, mas somente àquilo que o analista estaria preparado para acolher a fim de explicar a durabilidade e a extensão de uma interação" (2012, p. 109)

${ }^{6}$ A escolha de "ocidental" (assim como a escolha de "moderno") parte da compreensão já desenvolvida por Marilyn Strathern (2006), que entende por ocidental "o conjunto de ideias que deriva de uma fonte social com sua natureza própria, específica e singular, por contraste com a derivação das ideias melanésias" (2006, p. 38). No artigo em questão, o contraste é feito não apenas em contraposição à Melanésia, mas a sociedades outras. Para saber mais, ver Strathern, Marylin (2006) "Estratégias antropológicas". In. O gênero da Dádiva: Problemas com as mulheres e problemas com a sociedade Melanésia.
} 
imaginadas como conceitualmente distintas das relações que as unem" (STRATHERN, 2006, p. 40).

Já as concepções melanésias de pessoa, segundo a autora, precisam de um novo vocabulário, que permita falar em socialidade tanto no singular quanto no plural (impensável, portanto, nos modelos analíticos ocidentais tais como o são). Nesse sentido, a pessoa Hagen não é pensada enquanto entidade singular, mas como dividual, ou seja, "elas [as pessoas] contêm dentro de si uma socialidade generalizada (...)" e são compreendidas enquanto um "lócus compósito das relações que as produzem" (STRATHERN, 2006, p. 40-41).

Certamente, as noções de pessoa que fogem da construção "ocidental" são extremamente significativas e podem auxiliar na própria compreensão de propriedade(s) intelectual(ais) realizadas e representadas além do nosso arcabouço legal e moral sobre autoria e indivíduo. A ideia que compartilhamos da construção do indivíduo enquanto agente individual e singular, que combina, segundo Strathern (2006, p. 243), com a “conceptualização (derivada da noção de propriedade) de propriedade legítima" sustenta os pilares da nossa noção de autoria.

Como dar conta, dentro do nosso repertório analítico, por exemplo, da perspectiva dos povos melanésios onde as "continuidades de identidades entre pessoas e coisas podem ser dadas como certas" (STRATHERN, 2014, p. 408), enquanto que nos estudos de direito de propriedade euroamericanos, uma separação entre coisas e pessoas se torna condição necessária para seu funcionamento? Talvez a pessoa compósita Hagen e a noção ameríndia de pessoa possam nos apontar formas de compor esse universo de propriedades intelectuais/coletivas outras.

Para Strathern (2006), a ideia secular de que as pessoas são proprietárias delas mesmas e de seu trabalho, nos acompanha até hoje. É necessária uma compreensão de uma "autoria deslocada", que apreenda as relações tais como nos é dada (ou melhor, fabricada) nos contextos ameríndios. Isso significa compreender:

1. As relações entre sujeitos (criadores) e objetos de outra maneira (na nossa sociedade);

2. A autoria mediada por uma agência que não passe, necessariamente, pela propriedade intelectual tal como a concebemos;

3. A autoria enquanto uma série de práticas inacabadas que nem sempre podem ser domesticadas em um conceito único ou correlacionadas ao direito autoral. 


\section{Alguns casos emblemáticos e apontamentos finais}

Segundo o ISA (Instituto Socioambiental), os Kisêdjê são um grupo de língua Jê que habitam o Parque Indígena do Xingu, com uma população de aproximadamente 420 pessoas. O estilo particular de ritual, além dos grandes discos labiais que compõem esse povo, é um marco diferencial que - curiosamente - parece ter atraído o interesse de uma grande fábrica de calçados.

Em 2006, a Grendene iniciou um processo de parceria com os Kisêdjê, a fim de lançar uma coleção de sandálias que tivessem como tema a devastação do Rio Xingu e salientasse a importância de um discurso socioambiental protecionista. Segundo Marcela Coelho de Souza (2012), o contrato firmado incluía a cessão dos padrões gráficos daquela etnia, além de um comercial para a TV com a participação da top model brasileira Giselle Bündchen.

A vivência dessa experiência trouxe dois problemas importantes, segundo Marcela Coelho de Souza (2012). O primeiro se relacionava com o fato das pinturas femininas Kisêdjê serem relativamente pobres se comparadas à pintura masculina, colocando de imediato a "recriação" ou "restauração" de um padrão de pintura comum ao repertório alto-xinguano de seus vizinhos, visto que a modelo seria pintada e enfeitada pelos Kisêdjê. O outro momento, relatado por Coelho de Souza (2012), se refere ao que eles consideraram "quebra de contrato", quando, algum tempo depois da campanha ter sido finalizada, a comunidade reconheceu o reaproveitamento dos grafismos em outra linha de sandália da mesma empresa fabricante. Atentaremos, nesse artigo, nas pinturas recriadas pelos Kisêdjê.

A recriação de um padrão corporal é um ponto interessante para pensarmos as questões a respeito da autoria. Se pensarmos no conceito de autoria enquanto propriedade, a recriação pode ser assimilada como cópia ou até como plágio. O modelo da recriação de um padrão jamais visto pelos viventes Kisêdjê ${ }^{7}$, se subvertido ao nosso contexto, não pode ser delimitado como "criatividade", visto que se existe o criador, ele é o responsável pelo direito desse repertório. A percepção indígena sobre direito, criação e autoria parte de uma noção de pessoa coletiva/dual/compósita, e, consequentemente, de pessoa enquanto relações - que tampouco se resumem à legalidade das leis de direito autoral.

Um caso parecido sobre a autoria das pinturas se desenrolou com os Yawalapiti, grupo que vive no Alto Xingu e que contam com uma população de aproximadamente 260 pessoas. Em 2015, grafismos com ilustrações dos Yawalapiti nas sandálias havaianas abriram um leque

\footnotetext{
${ }^{7}$ E seu processo de xinguanização, como aponta Marcela S. Coelho de Souza.
} 
de discussões sobre direitos autorais e propriedade intelectual coletiva. Isso porque os grafismos são considerados uma propriedade coletiva e não um direito autoral exclusivo. A empresa de publicidade que representa a sandália obteve o direito de uso e reprodução dos grafismos coletivos do povo Yawalapiti para distribuição promocional em campanha específica de 10.000 sandálias. O contrato foi assinado por Anuiá Yawalapiti, firmado no valor de R \$ 7.500 em troca da cessão dos direitos de reprodução das ilustrações feitas por ele.

Os grafismos indígenas - tanto os Kisêdjê quanto os Yawalapiti - são conhecimentos tradicionais assegurados por algumas convenções específicas, como a Convenção da Diversidade Biológica, de 1992 e a Proteção Sui Generis, garantida pela Organização Mundial da Propriedade Intelectual (OMPI), em vigor desde 1970. Esses desenhos não encontram uma compreensão legal compatível com o direito autoral "ocidental”, visto que o que poderíamos considerar como direito autoral indígena é um direito coletivo da própria etnia. Dessa forma, a assinatura por Anuiá, que recriou os desenhos a partir de grafismos comuns a várias etnias do Parque do Xingu foi algo problemático, não assimilado sem controvérsias.

Outro ponto importante é lembrar que o grafismo, as pinturas e os enfeites não são joguetes nas relações que se encontram. Eles são dotados de agência, são objetos acionados ora enquanto pessoas, ora enquanto coisas - em um emaranhado de conexões que não versam apenas sobre direitos legais, mas sobre a forma de compor o mundo dentro do universo ameríndio. A pintura feminina Kisêdjê, por exemplo, foi recriada a partir de Pyj, uma moça (ou duas) que ocupara, há muitos anos, posições rituais particulares entre esse povo. Como nos conta Coelho de Souza (2012, p.226)

\begin{abstract}
"As moças que passam por isso alcançam uma posição especial, que afeta sua vida cotidiana. Essa transição é marcada pela imposição de um novo nome composto a partir do prefixo Pyj, pelo qual serão doravante conhecidas. Para dar exemplos, nos relatos mencionados, que se referem a instâncias históricas específicas do rito, as moças receberam os nomes de Pyj-kango-txi e Pyjkango, em um caso, e Wyj-nty-txi [nty, "chocalho"] e Wyj-nh«tep-txi [nh«tep, "ponta"], no outro".
\end{abstract}

Uma vez que a propriedade intelectual versa sobre uma certa construção de indivíduo, como compreender a noção de propriedade intelectual, e conseguintemente, de autoria, que está em jogo nesses dois casos?

É importante assinalar dois fatores: as pinturas não são apenas pinturas, e não existe um arcabouço legal que dê conta da potencialidade desses não-humanos. Ao acionar um certo 
tipo de grafismo ou de enfeite, de um lado se coloca a coletividade de um pensamento descontínuo, versus um outro tipo de racionalidade que apenas qualifica o objeto a fim de torná-lo transicionável. Por último, recriar ou apropriar uma "cultura" é um movimento de "constituição e diferenciação de entidades e identidades na Amazônia" (COELHO DE SOUZA, 2012, p. 246) que definem propriamente a vida humana.

A apropriação enquanto propriedade não parece fazer parte do universo ameríndio justamente porque aqui, diferente da propriedade privada de Locke, a pessoa é fabricada não enquanto posse, mas a partir da relação. Isso significa compreender que, enquanto sujeito criador, o universo indígena é compósito. Seu sujeito é coletivo e sua criação é compartilhada nos e pelos objetos.

Pensar outra forma de relação onde pessoas e coisas possam assumir formas sociais duais, ora coisa, ora pessoas, parece ser a saída apontada para estabelecer uma outra maneira de se construir a propriedade intelectual "moderna". Aqui conseguimos apreender, por exemplo, que recriar não é cópia, muito menos plágio. Sugerimos que o direito autoral pode ser coletivo e sua autoria compartilhada de diferentes maneiras - não apenas pela inventividade que sustenta novas relações (tais como os grafismos recriados ou até mesmo o padrão da pintura Yawalapiti feita a partir do universo comum xinguano), mas a partir de uma nova relação entre o sujeito (pessoa) criador e seu objeto (criação).

Trata-se de considerar a composição da pessoa plural, com autorias variadas, que viria como forma de reparar um modelo de propriedade intelectual circunstancial e incompleto. A propriedade intelectual, tal como ela é pensada na sociedade moderna, propõe uma cristalização das relações que se refletem na forma em que patentes, direitos autorias e proteções sui generis são pensadas.

O primeiro ponto, talvez o mais urgente, seria decompor o caráter indivisível da pessoa - e possivelmente seus respaldos legais seriam outros-, dos mais diversos, que não levassem apenas a posse como fato de direito. A criatividade que emana de uma outra composição de mundo sugerida pelo universo ameríndio deveria, de fato, ser o ponto de partida para aceitar um movimento pouco totalizador, com diferentes experiências de corporalidades.

Isso significa não só repensar nosso arcabouço legal sobre propriedade intelectual, mas também a nossa própria forma de ver o mundo. Sugerimos, assim como Strathern (2006), que não estamos apenas entrando nas relações e, consequentemente, separando corpos de nossas 
produções. Almejamos produzir relações tais como as pessoas melanésias ou, em outra escala, como as pessoas ameríndias.

\section{Referências Bibliográficas}

ANTÔNIO, Irati. “Autoria e Cultura na Pós-Modernidade”. In: Ci. Inf., Brasília, v. 27, n. 2 , p.189-192, mai - ago. 1998.

CARNEIRO DA CUNHA, Manuela. Os mortos e os outros: Uma análise do Sistema Funerário e da Noção de Pessoa entre os índios Krahó. São Paulo: Hucitec, 1978.

COELHO DE SOUZA, Marcela Stockler. "A pintura esquecida e o desenho roubado: contrato, troca e criatividade entre os Kisêdjê". Revista de Antropologia, v. 55, n. 1, p. 209-253, 2012.

DESCARTES, R. Discurso do método. 2. ed. São Paulo: Martins Fontes, 2001.

DUMONT, Louis. Introdução. In: Homo Hierarchicus. São Paulo: Edusp, 1997.

DURKHEIM, Émile. "Representações individuais e representações coletivas". In: Sociologia e Filosofia. Rio de Janeiro: Forense-universitária, 1970.

FOUCAULT, Michel. “Qué es un autor?”. In: Dialética, México, ano IX, n.16, 1969.

GEERTZ, Clifford. "Do ponto de vista dos nativos: a natureza do entendimento antropológico". In: O Saber Local - novos ensaios em antropologia interpretativa. Petrópolis: Vozes, 2012.

GOLDMAN, Márcio. "Uma categoria do pensamento antropológico: a noção de pessoa". In: Alguma Antropologia. Rio de Janeiro: Relume Dumará,1999.

LATOUR, Bruno. Reagregando o social: uma introdução à teoria do Ator-Rede. Salvador: Edufba, 2012.

LEVY-BRUHL, Lucien. El Alma Primitiva. Barcelona: Ediciones Península, 1947.

MAUSS, Marcel. "Uma categoria do espírito humano: a noção de pessoa, a noção do eu”. In Sociologia e Antropologia. São Paulo: Cosac \& Naify, 2003.

MORGAN, Lewis. "A sociedade antiga". In. Evolucionismo Cultural: textos de Morgan, Tylor e Frazer. (Org) Celso Castro. Rio de Janeiro: Zahar, 2005

RADOMSKY, Guilherme F.W. "Problemas e tensões entre as noções de produção, propriedade intelectual e cultura". In: Horizontes Antropológicos, Porto Alegre, ano 18, n. 37, p. 155-183, jan-jun. 2012. 
SEEGER, Anthony; DA MATTA, Roberto; VIVEIROS DE CASTRO, Eduardo. “A construção da pessoa nas sociedades indígenas brasileiras". Boletim do Museu Nacional, Série Antropologia, n. 32, p. 2-19. 1979.

STRATHERN, Marilyn. "Trabalho: a exploração em questão". In. O Gênero da Dádiva: Problemas com as mulheres e problemas com a sociedade melanésia. Campinas: Editora da Unicamp, 2006.

Paulo: Cosac Naify, 2014.

“Cortando a Rede”. In. O Efeito Etnográfico e outros ensaios. São "Os limites da autoantropologia". In. O Efeito Etnográfico e outros ensaios. São Paulo: Cosac Naify, 2014.

"O que busca a propriedade intelectual". In. O Efeito Etnográfico e outros ensaios. São Paulo: Cosac Naify, 2014.

VIVEIROS DE CASTRO, Eduardo \& BENZAQUEN DE ARAÚJO, Ricardo. "Romeu e Julieta e a Origem do Estado". In: Velho, Gilberto. (org.) Arte e Sociedade: Ensaios de sociologia e arte. Rio de Janeiro: Jorge Zahar Editores, 1977, pp. 130-169.

VIVEIROS DE CASTRO, Eduardo. Araweté: Os Deuses Canibais. Rio de Janeiro: Zahar, 1986

Sites consultados:

ISA (Instituo Socioambiental) - Acesso 13/07/2017

https://pib.socioambiental.org/pt/povo/kisedje

https://pib.socioambiental.org/pt/povo/yawalapiti

Sobre os Yawalapiti: (Acesso 12/07/2017)

https://brasil.elpais.com/brasil/2015/02/13/politica/1423839248 331372.html

http://www.efratamusic.com.br/conteudo.php?id=996\&id_secao=1

http://radioyande.com/default.php?pagina $=$ blog.php\&site $i d=975 \&$ pagina $i d=21862 \&$ tipo $=p$

ost\&post_id $=95$

Sobre os Kisêdjê: (Acesso 12/07/2017)

http://m.caras.uol.com.br/mobilesite/noticia/gisele-bundchen-a-top-dos-kisedje

http://www20.opovo.com.br/app/opovo/economia/2015/01/16/noticiasjornaleconomia,337793

5/imagens-que-valorizam-marcas.shtml

INTRATEXTOS, Rio de Janeiro, vol. 10, n.1, 2019, p. 1-17. ISSN 2176-6789.

DOI: 
Recebido em: Abril de 2018 Aprovado em: Fevereiro de 2018 